annual incidence of depression in the Canadian study was 2.1 per 1000 for men and 2.5 per 1000 for women. This compared with 2.0 and 5.0 per 1000 in men and 2.7 and 7.0 per 1000 in women in Finland and in Sweden (the Lundby Study), respectively. The ECA study reported an incidence of DSM-III major depression of 11 and 20 per 1000 for men and women, respectively, and the Scottish study found incidence to be 78 per 1000 among women for RDC major depression.

Differences of this magnitude are troubling. I agree with the Finnish investigators when they say that these differences may be influenced by diagnostic criteria and the length of the follow-up period. To these reasons I would add that different styles of interviewing and variant forms of questions may be implicated. Nevertheless, I suggest that the rates from Canada, Finland and Sweden are more reasonable than the higher rates, because they fit better with evidence that psychiatric disorders are often chronic or recurrent and that, under such conditions, incidence is typically low relative to prevalence.

The most compelling reason, however, for doubting the credibility of the higher rates relates to their long-term implications. Suppose that the Scottish and USA rates pertain to a group of women aged 20 who are at risk for a first-ever major depression. By the time they are 35 years old, virtually all of the Scottish cohort would have succumbed to this disorder. Using the not-quite-so high data from the USA, if all women in such a cohort survived to age 70 , all would have experienced at least one episode of major depression. If everybody at some time has a 'major depression', is major depression the serious disorder that clinical evidence indicates it is?

Eaton, W. W., Kramer, M., Anthony, J. C., et al (1989) The incidence of specific DIS/DSM-III mental disorders: data from the NIMH Epidemiologic Catchment Area Program. Acta Psychiatrica Scandinavica, 79, 163-178.

HaGnell, O., Essen-Möller, E., LANKe, J., et al (1990) The incidence of mental illness over a quarter of a century. Stockholm, Sweden: Almquist \& Wiksell.

LeHTnNen, V., VeuOLA, J., Lndholx, T., et al (1996) Incidence of mental disorders in the Finnish UKKI Study. British Journal of Psychiatry, 168, 672-678.

MuRPhy, J. M., Ouvier, D. C., Monson, R. R., et al (1988) Incidence of depression and anxiety: the Stirling County Study. American Journal of Public Health, 78, 534-540.

Surtees, P. G., Sashimharan, S. P. \& Dean, C. (1986) Affective disorder amongst women in the general population: a longitudinal study. British Journal of Psychiatry, 148, 176-186.

Department of Psychiatry

J. M. MURPHY

Harvard Medical School

Boston, MA 02114-2698

\section{Women and psychiatry}

SIR: Crimlisk \& Welch (1996) discuss interesting data concerning women as psychiatrists and gender differences in aptitude for psychiatry among medical students. The latter topic has also been recently reviewed by Eagles (1996). However, their interpretation of the Royal College of Psychiatrists census material may not be entirely correct. The absence of a gradient in the proportion of women in the various training grades does not rule out a cohort effect as an explanation of the relative dearth of female consultants. A breakdown of the proportion of women in the consultant grade at various seniority levels would be needed to prove or disprove this. Unfortunately, the census does not yet obtain this detail but some information from other sources indicates that women are relatively over-represented in the earlier years of consultant status. Ideally, prospective studies of the current trainee cohort would be needed to assess the relative success rate of men and women in moving to the consultant grade.

This does not detract from the value of the suggestions made by Crimlisk \& Welch and by Eagles that flexibility of working patterns should be maximised in the training grades and in career posts to enable all doctors, particularly those with domestic commitments, to pursue their chosen career path. Encouragingly, recent meetings between representatives of the College and the Department of Health have established a considerable measure of agreement on the desirability of such flexibility and a commitment towards finding methods of achieving it.

Crnalsk, H. \& Welch, S. (1996) Women and psychiatry. British Journal of Psychiatry, 169, 6-9.

EAGles, J. M. (1996) Gender differences in attitudes and recruitment into psychiatry. Psychological Reports, 78, 653-654.

\section{The General Infirmary at Leeds}

D. STORER

\section{Great George Street}

Leeds LS1 3EX

SIR: We read with interest the editorial by Crimlisk \& Welch (1996). We wish to broaden the scope of their review by focusing firstly, on the influences of gender on psychotropic drug use and secondly, on drug metabolism. Yonkers et al (1992) have reviewed the theoretical background and the evidence supporting gender-related differences in pharmacokinetic and pharmacodynamic properties of psychotropic medication. Their findings suggest that young women seem to respond better to and 
require lower doses of antipsychotic medication and benzodiazepines than young men. Gender is considered to be an important variable in the processes of absorption, distribution, metabolism and excretion of drugs (Fletcher et al, 1994). Gastric acid secretion, gastro-intestinal blood flow, proportions of muscular and adipose tissue, amount of drug-binding proteins, gender-specific cytochrome p450 isozymes, physiological and hormonal changes during the menstrual cycle, and renal blood flow have been highlighted by Fletcher $e t$ al as factors that may contribute to gender-related differences in pharmacokinetics. Cytochrome p450, the primary oxidative pathway of drug metabolism and a major site of drug, drug-diet and drug-disease/ condition interactions (Rogers, 1994), is increasingly recognised as important in psychopharmacology (von Moltke et al, 1994). Isozymes of cytochrome p450 that are specific to females are known to exist and are reported to have significant influence on side-chain oxidation, especially on C-oxidation (Fletcher et al, 1994). Gender influences on psychopharmacology are therefore important. Future research should focus not only on the pathophysiology of conditions restricted to or more relevant in women, but also aim to provide more gender-specific information on drug disposition and clinical effect.

Crnousx, H. \& Welch, S. (1996) Women and psychiatry. British Journal of Psychiatry, 169, 6-9.

Fletcher, C. V., Acosta, E. P. \& StryxowsKi, J. M. (1994) Gender differences in human pharmacokinetics and pharmacodynamics. Journal of Adolescent Health, 15, 619-629.

RoGerRs, A. S. (1994) The role of cytochrome P450 in developmental pharmacology. Journal of Adolescent Health, 15, 635-640.

von MoltKe, L. L., Greenblatt, D. J., Harmatz, J. S., et al (1994) Cytochromes in psychopharmacology. Journal of Clinical Psychopharmacology, 14, 1-4.

YonkKRrs, K. A., KANDO, J., Kole, J. O., et al (1992) Gender differences in pharmacodynamics and pharmacokinetics of psychotropic medication. American Journal of Psychiatry, 149, 587-595.

Shaftesbury Clinic

61 Glenburnie Road

London SE17 7DJ

Department of General Psychiatry

S. R. JACOBSON

St George's Medical School

London SWI7 ORE

\section{Melancholia and response to ECT}

SIR: I was interested to read the study by Hickie et al (1996) but am keen to offer an alternative interpretation of their results. They found that degree of psychomotor retardation and presence of psychotic ideas better predict response to ECT than the initial severity of depression as measured by the Hamilton Rating Scale for Depression (HRSD). They conclude that this is supportive of the validity of melancholia, a postulated sub-type of depression.

The deficiencies of the HRSD have been well documented (Gibbons et al, 1993), especially for a group of predominantly elderly patients with a wide age-range and high rates of concurrent medical problems (Snaith, 1993), such as Hickie et als sample. It is therefore quite likely that psychomotor retardation and psychotic ideas were simply much better markers of severe depressive illness in this study than the HRSD score was. Therefore, a person with psychomotor retardation and psychotic ideas but with a lower HRSD score is likely to be more depressed than one with a high score but lacking these major symptoms. This is borne out by Hickie et $a l s$ findings of stronger correlations between the initial Global Assessment of Functioning (GAF) and psychotic symptoms and retardation than between the initial HRSD and GAF scores. Viewed in this light, Hickie et al's findings should be interpreted as showing that the likelihood of response to ECT depends upon the initial severity of illness and that severe illness is best characterised by poor global functioning and the presence of psychotic thought or psychomotor retardation. There is no need to postulate a sub-type of depression.

Gibbons, R. D., Clark, D. C. \& Kupfer, D. J. (1993) Exactly what does the Hamilton depression rating scale measure? Journal of Psychiatric Research, 27, 259-273.

Hickie, I., Mason, C., PArker, G., et al (1996) Prediction of ECT response: validation of a refined sign-based (CORE) system for defining melancholia. British Journal of Psychiatry, 169, 68-74.

SNArTH, P. (1993) What do depression rating scales measure? British Journal of Psychiatry, 163, 293-298.

Hellesdon Hospital

J. M. G. Winliams

Drayton High Road

Norwich NR6 SBE

\section{Urine screening for drugs and trazodone}

SIR: I write to draw the reader's attention to the interesting but spurious appearance of positive amphetamine results in the presence of trazodone on routine drug screening with polyclonal antibodies such as EMIT-1 (originally produced by SYVA). Reporting of amphetamines, therefore, on routine drug screening while a patient is on trazodone may be spurious. A confirmatory test 